\title{
Atribuições de uma ouvidoria: opinião de usuários e funcionários'
}

\section{Ombudsman's attributions: the opinion of users and ombudsmen}

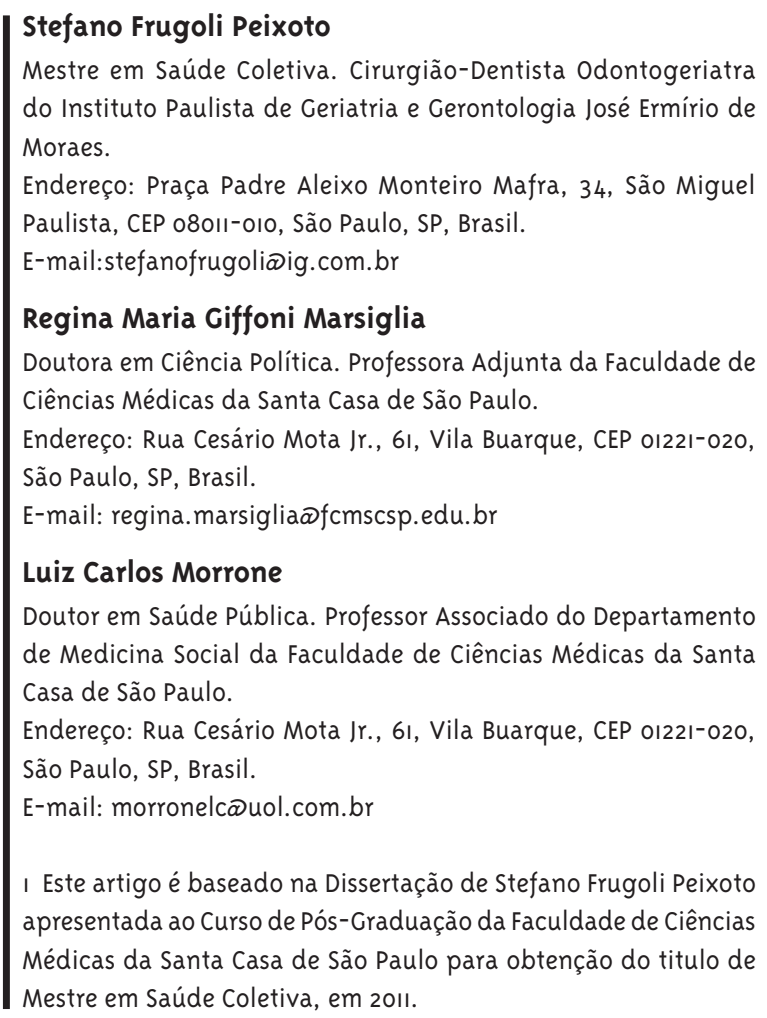
apresentada ao Curso de Pós-Graduação da Faculdade de Ciências Médicas da Santa Casa de São Paulo para obtenção do titulo de Mestre em Saúde Coletiva, em 2011.

\section{Resumo}

Objetivos: investigar a opinião de usuários e funcionários da ouvidoria de uma instituição geriátrica do SUS (Sistema Único de Saúde) sobre os serviços prestados por ela. Métodos: pesquisa quantitativa e qualitativa. Foram analisadas as manifestações da base de dados da ouvidoria (2008 a 2010); realizadas entrevistas semiestruturadas com 15 usuários e 4 ouvidores de uma instituição geriátrica do SUS localizada na cidade de São Paulo, Brasil. As respostas foram analisadas pelo método de análise de conteúdo. Resultados quantitativos: nesse período ocorreram 1.050 solicitações de informação, 226 reclamações, 10 elogios, 7 denúncias, 4 sugestões e 3 expressões livres. Várias solicitações de informação (568) e reclamações (168) estavam relacionadas a dificuldades de acesso a consultas em especialidades ou a clínica geral. Resultados qualitativos: a maioria dos usuários entrevistados informou ter procurado a ouvidoria para reclamar de negligência ou descortesia dos funcionários. Os ouvidores entrevistados consideraram que a maioria dos usuários que demandam o setor acredita que seus problemas seriam solucionados. Conclusão: este estudo mostrou que na instituição pesquisada a ouvidoria funciona principalmente fornecendo informações. Há a possibilidade de que essas informações sejam, na verdade, reclamações erroneamente classificadas. 0 excesso de demanda existente na instituição acaba repercutindo diretamente no papel da ouvidoria, distorcendo suas atividades. Alguns problemas poderiam ser evitados por ações inerentes à própria instituição geriátrica, como melhora no acolhimento e na organização dos serviços. 0 motivo mais comum de demanda à ouvidoria referiu-se a dificuldades no acesso aos serviços de saúde.

Palavras-chave: Ouvidoria; Serviços de atendimento; Serviços de saúde para idosos; Satisfação do paciente; Recursos humanos em saúde. 


\section{Abstract}

Objectives: To investigate users and ombudsmen's opinion concerning the services of the ombudsman's office in a geriatric institution of SUS (Brazilian National Health System). Methods: Quantitative and qualitative research. Data from the ombudsman's office database (2008 to 2010) were analyzed. Semi-structured interviews were carried out. Subjects were 15 users and four ombudsman office workers of a geriatric institution of SUS located in São Paulo, Brazil. Answers were analyzed by content analysis method. Quantitative results: In this period there were 1050 information requests, 226 complaints, 10 praises, 7 denunciations, 4 suggestions and 3 other declarations. Several information requests (568) and complaints (168) were related to difficulties in obtaining primary and secondary medical care. Qualitative results: Most of interviewed users seek the ombudsman's office to complain about employees' negligence or discourtesy. The ombudsmen interviewed considered that most of users seek ombudsman's office because they believed that their problems would be solved. Conclusion: This study showed that this ombudsman's office is mostly providing information. However, complaints could be erroneously classified as information. Excess of demand in this institution reflects directly on the role of the ombudsman's office, causing distortion of its activities. Some of the problems could be avoided by actions taken by the geriatric institution itself, such as improving the quality and the organization of the services and reception. Difficulties in obtaining medical care were the most commonly reported problems.

Keywords: Ombudsman; Answering Services; Health Services for the Aged; Patient Satisfaction; Human Resources in Health.

\section{Introdução}

O primeiro ombudsman surgiu há mais de três séculos, na Suécia. 0 rei Karl II ficou, por 17 anos, fora de seu país, envolvido na guerra contra Rússia, Dinamarca, Polônia e Saxônia. Nesse período, foi criado o cargo de ombudsman (termo sueco que significa, em português, representante) do rei, cuja principal função era supervisionar os serviços dos funcionários do governo. Somente após quase 200 anos, em 1809, o parlamento sueco reativou a função de ombudsman. Novamente em guerra, o então rei estava cativo dos russos; e Lars Augustin Mannerheim foi nomeado para a função, com a responsabilidade de defender o cidadão contra os excessos da burocracia. À palavra ombudsman passou-se a agregar um sentido de "defensor do cidadão" ou "do povo" (Ombudsman Saskatchewan, 2010).

Aos poucos, a profissão foi colocando-se como mediadora entre a população e as administrações públicas, adquirindo características próprias, dependendo da localidade ou país.

No Brasil, o profissional ombudsman ficou mais conhecido como ouvidor. No período colonial (1500-1822) a função primordial do ouvidor geral era inversa da atual, ou seja, era reportar ao rei de Portugal o que ocorria na colônia. Somente em 1823 , logo após a independência, surgiu o ouvidor como “Juízo do Povo", ao qual a população poderia recorrer para denunciar atos de injustiça contra ela. Não teve, contudo, êxito marcante.

Finalmente, em 1983, juntamente com o processo de redemocratização, a ouvidoria nos moldes atuais começou a ser discutida no Brasil. Em 1985 surgiu a primeira, na empresa Rhodia. Era, portanto, uma ouvidoria privada. No ano seguinte, a primeira pública: a Ouvidoria Municipal de Curitiba. No âmbito estadual, o Paraná foi a primeira UF a instituir a sua, em 1991. A Lei Federal n 8.490, de 19 de novembro de 1992, instituiu a Ouvidoria Geral da República. Com relativa rapidez, as ouvidorias começaram, então, a se propagar pelo país. No Estado de São Paulo, a Lei no 10.294, de 1999 (a Lei de Defesa do Usuário de Serviços Públicos do Estado de São Paulo) (São Paulo, 1999a), que tornou obrigatória a presença da ouvidoria nas Secretarias de Estado, e o Decreto $\mathrm{n}^{0} 44.074$, de $1^{0}$ de julho de 1999, que estabeleceu a competência dos ouvidores, são importantes marcos 
na legislação paulista com relação ao tema (São Paulo, 1999b).

A Ouvidoria Geral do SUS pertence à Secretaria de Gestão Estratégica e Participativa, vinculada ao Ministério da Saúde, e foi criada pelo Decreto $\mathrm{n}^{0}$ 4.726, de 9 de junho de 2003. Em 2006, foi implantado o OuvidorSUS -sistema informatizado que acompanha o tratamento das manifestações pelos órgãos responsáveis. Nenhuma legislação por nós estudada confere à ouvidoria poderes deliberativos: ela pode opinar, sugerir, mediar, instruir, mas não tem capacidade decisória.

As ouvidorias procuraram auxiliar o processo de construção da cidadania nas últimas décadas, em nosso país. São órgãos cuja função principal é "ouvir” a manifestação acerca dos serviços prestados, intervindo na relação entre o usuário e a administração pública. O conhecimento da opinião dos usuários em relação aos serviços públicos é importante instrumento auxiliar para planejamento e tomada de decisões. Também na rede privada, de modo similar, as ouvidorias intervêm na relação entre o consumidor e a empresa. Porém as ouvidorias privadas têm uma característica clientelista - procuram apoiar o reclamante desde que não ocorra interferência com a maximização dos lucros da empresa. Ao contrário, as ouvidorias públicas são de cunho universalista e tentam estimular a propagação da cidadania e da gestão participativa (Pinto e Lyra, 2009).

Este trabalho tem o intuito de investigar se esse senso de cidadania e de participação está presente entre os que demandam uma ouvidoria pública. Que esses usuários esperam da ouvidoria? Além disso, para corroborar com o ideal do Ministério da Saúde (Brasil, 2009), que preconiza a integração do conhecimento da população com o dos servidores públicos, investigou-se também a opinião dos ouvidores.

\section{Objetivos}

Investigar a opinião de usuários e de funcionários de uma ouvidoria pública sobre as atribuições e os serviços prestados por ela.

\section{Metodologia}

Pesquisa descritiva quantiqualitativa. $\mathrm{Na}$ abordagem quantitativa foram analisados os tipos de manifestações que chegaram à ouvidoria em 2008, 2009 e 2010. As demandas foram obtidas através do banco de dados do próprio setor. $\mathrm{Na}$ abordagem qualitativa foram realizadas entrevistas semiestruturadas com 15 usuários que procuraram a ouvidoria no lapso de uma semana típica de funcionamento, utilizando uma amostra do tipo acidental, e também com quatro funcionários da ouvidoria. Dos entrevistados foram obtidas informações sobre gênero, faixa etária, naturalidade, ocupação, grau de escolaridade, situação salarial e tempo de trabalho na ouvidoria. A entrevista dirigida aos usuários baseou-se em três perguntas: Por que recorreu à ouvidoria? O que você espera que a ouvidoria faça em relação à sua manifestação? Qual é, em sua opinião, a função da ouvidoria? O roteiro da entrevista aos funcionários, por sua vez, baseou-se nas seguintes perguntas: Quais os motivos mais frequentes que levam o usuário a procurar a ouvidoria? O que os usuários esperam da ouvidoria? Você crê que a ouvidoria contempla a expectativa dos usuários?

As respostas, tanto dos usuários como dos funcionários, às perguntas abertas foram analisadas pelo método de análise de conteúdo (Bardin, 1979; Marconi e Lakatos, 1988; Minayo e col., 1993). Foram cotejados os resultados dos dados quantitativos com as observações dos usuários e dos funcionários e as finalidades e competências apresentadas pela legislação federal (Brasil, 2006) e estadual sobre as ouvidorias.

O projeto desta pesquisa foi aprovado pelo Comitê de Ética em Pesquisa em Seres Humanos da Irmandade da Santa Casa de Misericórdia de São Paulo, sob o parecer nº oog/11.

\section{Resultados}

\section{Dados quantitativos}

As demandas dos usuários que procuram a ouvidoria desta instituição geriátrica são denominadas de manifestações e classificadas pelos ouvidores em:

1. Reclamações: descontentamento do usuário com a instituição ou mesmo com outros órgãos, sejam públicos ou privados.

2. Solicitações de informação: quando o usuário tem dúvidas em relação aos serviços, organização, horários etc. da instituição ou mesmo de outros 
órgãos, sejam públicos ou privados.

3. Elogios: demonstração de satisfação do usuário com serviços recebidos.

4. Sugestões: propostas que o usuário apresenta no intuito de melhorar a qualidade de serviços prestados.

5. Denúncias: acusações feitas a uma ou mais pessoas por suposta falta, contravenção ou suposto crime efetuado por ela(s). Se, por exemplo, algum cidadão contata a ouvidoria e diz que seu vizinho, idoso, está sendo vítima de maus-tratos, a manifestação é caracterizada como denúncia.

6. Expressões livres: caso não possam ser classificadas nas categorias acima.

As manifestações são também categorizadas na chamada classificação técnica, em:

1. Procedimento operacional: manifestações referentes ao funcionamento, tanto físico como organizacional (engrenagem) da instituição geriátrica, desde falta de profissional médico a vazamento no banheiro.

2. Recursos humanos: aquelas relacionadas à maneira como o funcionário atende o usuário, geralmente interpretado pelo usuário como descaso ou rudeza no tratamento.

3. Competência de outro órgão: aquelas relativas a outras instituições ou serviços que não são da instituição geriátrica, como insatisfação com o atendimento médico de uma UBS (unidade básica de saúde) ou de um convênio médico privado.

Na Tabela 1 apresentamos dados sobre as de- mandas dos usuários entre 2008 e 2010. Podemos observar que as Solicitações de informação e as Reclamações foram as duas mais frequentes, correspondendo a $80,8 \%$ e $17,4 \%$ das manifestações, respectivamente, perfazendo $98,18 \%$ do total - por essa razão, analisamos mais detalhadamente os dados desses dois tipos de manifestação (Tabelas 3 e 4). Pela quantidade de solicitações de informação supõe-se que a ouvidoria tem trabalhado como setor de informações. $O$ usuário tem direito à informação, como prevê a legislação (Lei n ${ }^{0} 10.294$, de 20 de abril de 1999, artigos $4^{\circ}$ e $5^{\circ}$ ), porém, fornecer diretamente a informação não é função da ouvidoria - ela provavelmente está executando esse serviço para dinamizar o fluxo de atendimento.

Na Tabela 2 podemos constatar que cerca de 70\% das manifestações referiram-se ao funcionamento da instituição geriátrica (Procedimento operacional) e que $7 \%$ estavam ligadas a problemas com Recursos humanos, o que nos leva a pensar que, ao menos em tese, a prestação dos serviços poderia ser melhorada por meio de ações da própria instituição geriátrica.

A Tabela 3 apresenta as manifestações do tipo Solicitação de informação, por serviços prestados, mais frequentes. A maioria estava relacionada com o acesso: obtenção de tratamento nas especialidades como geriatria, ortopedia, fisioterapia e odontologia (261), dificuldades para agendamento (157) e informações relativas ao cadastro na instituição (150). Esses três itens somam 568 das 1.050 solicitações de informação (54\%).

Tabela I - Número e proporção (\%) de manifestações que chegaram à ouvidoria de uma instituição geriátrica, segundo tipo e semestre (sem.), em São Paulo, SP, entre 2008 e 2010

\begin{tabular}{|c|c|c|c|c|c|c|c|}
\hline Tipo & $\begin{array}{l}\text { I Sem }^{\circ} \text {. } \\
2008\end{array}$ & $\begin{array}{c}2^{\circ} \mathrm{Sem} \\
2008\end{array}$ & $\begin{array}{l}1^{\circ} \text { Sem. } \\
2009\end{array}$ & $\begin{array}{l}2^{\circ} \mathrm{Sem} \\
2009\end{array}$ & $\begin{array}{l}1^{\circ} \mathrm{Sem} \\
2010\end{array}$ & $\begin{array}{l}2^{\circ} \text { Sem } \\
2010\end{array}$ & $\begin{array}{c}\text { Total de manifestações } \\
\qquad N^{\circ}(\%)\end{array}$ \\
\hline Solicitação de informação & 62 & 48 & 285 & 268 & 221 & 166 & $1050(80,8)$ \\
\hline Reclamação & 30 & 59 & 44 & 31 & 44 & 18 & $226(17,4)$ \\
\hline Elogio & 2 & - & 1 & 1 & 3 & 3 & $10(0,7)$ \\
\hline Denúncia & 1 & 6 & - & - & - & - & $7(0,55)$ \\
\hline Sugestão & 1 & । & - & 2 & - & - & $4(0,3)$ \\
\hline Expressões livres & 1 & I & 1 & - & - & - & $3(0,25)$ \\
\hline TOTAL & 97 & 115 & 331 & 302 & 268 & 187 & $1300(100,0)$ \\
\hline
\end{tabular}

Fonte: banco de dados da ouvidoria de uma instituição geriátrica do SUS, São Paulo, 20 ı.. 
Tabela 2 - Número e proporção (\%) de manifestações que chegaram à ouvidoria de uma instituição geriátrica, segundo classificação técnica, por semestre, em São Paulo, SP, entre 2008 a 2010

\begin{tabular}{lccccccc} 
Classificação técnica & $1^{\circ}$ Sem. & $2^{\circ}$ Sem. & $1^{\circ}$ Sem. & $2^{\circ}$ Sem. & $1^{\circ}$ Sem. & $2^{\circ}$ Sem. & Total de manifestações \\
& 2008 & 2008 & 2009 & 2009 & 2010 & 2010 & $894(68,75 \%)$ \\
Procedimento operacional & 46 & 66 & 277 & 248 & 198 & 59 & $91(7,0 \%)$ \\
Recursos Humanos & 11 & 9 & 14 & 15 & 24 & 18 & 110 \\
Competência de outro órgão & 40 & 40 & 40 & 39 & 46 & 110 & $18,25 \%)$ \\
TOTAL & 97 & 115 & 33 & 302 & 268 & 187 & $1300(100,0 \%)$ \\
\hline
\end{tabular}

Fonte: banco de dados da ouvidoria de uma instituição geriátrica do SUS, São Paulo, 20 ı.

Tabela 3 - Número e proporção (\%) de manifestações do tipo Solicitação de informação que chegaram à ouvidoria de uma instituição geriátrica, em relação ao serviço prestado, São Paulo, SP, entre 2008 e 2010

\begin{tabular}{lcc} 
& N de manifestações & (em relação ao total) \\
Especialidades médicas e correlatas & 261 & 24,85 \\
Agendamento médico & 157 & 14,95 \\
Cadastro na instituição geriátrica & 150 & 14,28 \\
Exames complementares & 139 & 13,23 \\
Medicamentos e receituários & 95 & 9,04 \\
Proteção e defesa da pessoa idosa & 74 & 7,04 \\
Transferência de profissional & 45 & 4,28 \\
Outros & 129 & 12,28 \\
TOTAL & 1050 & 100,0 \\
\hline
\end{tabular}

Fonte: banco de dados da ouvidoria de uma instituição geriátrica do SUS, São Paulo, 2010.

Tabela $4_{4}$ - Número e proporção $(\%)$ de manifestações do tipo Reclamação que chegaram à ouvidoria de uma instituição geriátrica, em relação ao serviço prestado, São Paulo, entre 2008 e 2010

\begin{tabular}{lcc} 
& $N^{0}$ de manifestações & \% (em relação ao total) \\
Agendamento médico & 92 & 40,70 \\
Especialidades médicas e correlatas & 76 & 33,62 \\
Exames complementares & 32 & 14,15 \\
Medicamentos e receituários & 11 & 4,86 \\
Outros & 15 & 6,63 \\
TOTAL & 226 & 100,0 \\
\hline
\end{tabular}

Fonte: Banco de dados da ouvidoria de uma instituição geriátrica do SUS, São Paulo, 2010. 
As Reclamações são manifestações que devem ser analisadas com cautela, uma vez que refletem a insatisfação do usuário. Como já vimos, é o segundo tipo de manifestação mais frequente na ouvidoria. De acordo com a Tabela 4, a maioria recaiu sobre o setor de Agendamento médico: demora na obtenção de vaga de retorno, não desmarcação prévia de consulta, falta de cortesia dos funcionários, demora no atendimento. Em segundo lugar, apareceram as dificuldades de acesso às Especialidades médicas e correlatas, como geriatria, ortopedia, pneumologia, odontologia, psicologia, fisioterapia, terapia ocupacional. Exames complementares extraviados, atrasados, demorados ou não efetuados, porque o equipamento necessário para a realização do exame se encontrava em manutenção, também estiveram entre as mais frequentes. Algumas manifestações relacionadas com agendamento nem sempre ocorreram por excesso de demanda, estando ligadas a problemas organizacionais, como agendamento equivocado, tratamento descortês e exame desmarcado sem aviso prévio.

\section{Demandas e observações dos usuários}

\section{Perfil dos usuários entrevistados:}

Quinze usuários foram entrevistados em fevereiro de 2011, sendo 12 do sexo feminino. Muitos vieram do interior paulista ou eram migrantes nordestinos. Apresentavam, em sua maioria, baixa escolaridade e baixa renda familiar. A maior parte residia com familiares.

\section{A visão dos usuários sobre os serviços da ouvidoria}

A descortesia e a falta de empatia com o paciente - interpretados por este como desrespeito - foram elementos que pesaram na insatisfação do usuário. Essa insatisfação pode gerar sensações de mágoa ou de agressividade, uma vez que o usuário ou paciente, ao procurar serviços públicos, principalmente se sua saúde estiver abalada, necessita também de apoio, de acolhimento (Scanagatta, 2009). No caso de uma instituição geriátrica essa situação se agrava, visto que o usuário é idoso e pode estar se sentindo ainda mais fragilizado.

Não destratem o idoso... Se tem muita gente, que encaminhem a gente pra outro local.
Tem que colocar funcionários jovens na recepção. Velho não tem paciência pra atender outro velho.

Notou-se que, na visão de alguns usuários, a longa espera por um atendimento médico associada a uma consulta muito rápida, distraída ou a uma terapêutica de saúde de uso corrente ou de conhecimento popular, levou a uma percepção de displicência ou negligência por parte do profissional.

Médico não examina: só lê o prontuário e repassa os medicamentos que o paciente já está usando... Isso até eu sei fazer.

Demorou três meses para eu ser atendido no Ortopedista; a consulta foi rápida, não pediu um exame, nem nada, e só me passou uma dipirona. Isto até um feirante passa.

A dentista trabalhava distraída, enquanto conversava. [...] Me arranhou a boca. Foi horrível...

Houve uma tendência do usuário de se queixar da organização da instituição, do longo lapso na espera para agendamento de consultas e de exames e do número reduzido ou absenteísmo de médicos. A demora da recepção ao atender o usuário também foi comentada. Na fala dos entrevistados, novamente a sensação da falta de atenção com o idoso se fez presente:

Se o médico só chega às 1o horas ou 11 horas, então não agendem a consulta para as 7 horas.

Os funcionários da recepção devem ser mais rápidos... Ficam ali, conversando... E a gente esperando.

Todavia, foi comentado que no setor saúde as demoras são comuns, e que o usuário deveria estar familiarizado com os atrasos:

Consultas sempre demoram... Pode ser particular, convênio... Tem gente que não tem paciência.

A desconfiança sobre as informações fornecidas pelo servidor público durante o atendimento também esteve presente pelo menos em uma das entrevistas. 0 trecho do depoimento citado abaixo identifica essa situação. Entretanto, pode revelar confiança na ouvidoria:

A manicure falou que já tava no horário dela sair e que ela não ia me atender. Então, eu fui checar na ouvidoria se era verdade... 
Foi comentado pelos entrevistados que muitos, a despeito de estarem insatisfeitos com um serviço, não reclamam com medo de retaliação da instituição. Outros temem prejudicar algum funcionário, e também não procuram a ouvidoria:

Eu não tenho medo de reclamar. Muitos têm medo, e não reclamam...

Naquele dia todo mundo foi na ouvidoria, mas só meu marido assinou.

Alguns elogios para a ouvidoria, contudo, fizeram-se presentes:

Os funcionários dão atenção não só ao idoso, mas ao acompanhante também.

Na ouvidoria tratam a gente com respeito.

Ao sair da ouvidoria, a assistente social vem nos perguntar se fomos bem atendidos.

Só tenho que agradecer o governo, que fez este centro de saúde pra nós...

Convém ressaltarmos que alguns elogios, coincidenteme nte ou não, ocorreram quando a ouvidoria conseguiu resolver a demanda de forma rápida, dentro da expectativa do usuário.

\section{Observações dos funcionários}

\section{Perfil dos funcionários entrevistados:}

Os funcionários eram todos do sexo feminino e tinham entre 38 e 53 anos de idade: três assistentes sociais, uma das quais graduanda em direito, e uma oficial administrativa. Estavam trabalhando no setor há pelo menos três anos e meio.

\section{A visão dos funcionários sobre os serviços da} ouvidoria

$\mathrm{Na}$ ótica das funcionárias entrevistadas, a expectativa fundamental do usuário em relação à ouvidoria é de que esta solucione seus problemas, de preferência de forma imediata.

Eu te digo que 9o\%... 95\% esperam que a gente resolva o problema deles.

O que eles esperam é a resolução imediata.

Foi apontado também que, quando a expectativa em relação ao atendimento não é atingida, o usuário costuma procurar a ouvidoria.
Geralmente eles reclamam quando a expectativa dele com relação à consulta, seja de que profissional for, não é atendida. A expectativa dele fica abaixo do que ele realmente gostaria de ter como atendimento...

No entanto, na opinião de todas as entrevistadas a esmagadora maioria das manifestações tem origem na grande demanda de serviços, sempre maior que a oferta.

Eu acho que o problema dessa instituição é um problema [...] de acesso...

Algumas funcionárias creem que a maioria dos usuários vai ficando satisfeita à medida que lhe é explicada a função da ouvidoria, ainda que não ocorra a resolução da sua queixa, principalmente se esta explicação é realizada de maneira acolhedora.

A gente observa que, [...] mesmo não conseguindo a resolutividade, só o apoio que você deu, a intenção de ajudar, de acolher... Ele já sai satisfeito, mesmo que não seja favorável [...] o desfecho final...

Foi apontada a ausência de dados qualitativos nos relatórios da ouvidoria, especialmente quanto à opinião do usuário sobre os serviços do setor.

As entrevistadas acreditam que a visão do usuário, no que concerne à função da ouvidoria, é incorreta, pois ele crê que o setor tem poder deliberativo ou uma influência maior sobre as decisões dos serviços prestados do que na realidade possui. Porém, sempre que possível a ouvidoria resolve a manifestação do usuário informalmente, anotando a procura da ouvidoria, mas evitando a instauração de processos, assim desburocratizando e agilizando a resolução do problema e, consequentemente, satisfazendo o usuário. Essa atitude vem ao encontro do que prevê o artigo $1^{0}$ do Decreto $n^{0} .44 .074$, de $1^{\circ}$ de julho de 1999, nos incisos III e IX,respectivamente, "facilitar ao máximo o acesso do usuário do serviço à ouvidoria, simplificando seus procedimentos" e "atuar na prevenção e solução de conflitos."

Até porque a ouvidoria não faz só o trabalho de ouvidoria. [...] infelizmente [...] mesmo que não seja um trabalho nosso, a gente consegue até agilizar o processo para justamente o usuário sair satisfeito.

Quanto ao tratamento descortês, foi sugerido que ocorresse periodicamente uma capacitação que en- 
sinasse e estimulasse os funcionários a fornecerem um bom tratamento para com os idosos, de maneira padronizada:

Existe um funcionário que respeita o idoso, ele vai se mostrar atencioso, acolhedor... E existem outros que não... Mas não existe uma cobrança específica de um padrão no atendimento para o idoso, uma capacitação mais [...] continuada, permanente, neste sentido.

\section{Discussão}

A obtenção dos dados quantitativos nos forneceu uma visão panorâmica, facilitando reconhecer, grosso modo, as necessidades do usuário da ouvidoria (Silveira e col., 2009).

Após a análise dos itens, pudemos observar que há uma grande dificuldade de acesso aos serviços - "o problema dessa instituição é um problema [...] de acesso...", como comentou uma das funcionárias entrevistadas. Um grande número de reclamações também recaiu na área médica, coincidindo, nesse aspecto, com estudo de Pereira (2002), que analisou as ouvidorias de dois hospitais públicos de Porto Alegre, entre 1990 e 1998.

Foi comentado por alguns usuários o receio que muitos tinham de se manifestar através da ouvidoria, com temor de represália por parte dos funcionários da instituição. Grubba (2006) coloca como necessário o fortalecimento da autonomia dos usuários, mas também como um dos desafios a ser enfrentado pelas instituições prestadoras de serviços de saúde, e sugere construir com o usuário vínculos de confiança. 0 medo que ainda se tem de retaliação por parte de uma instituição ou de alguém que seja socialmente considerado superior pode dever-se ao fato do Brasil possuir longo histórico de sociedade autoritária, patrimonialista e dependente (Ribeiro, 2010), não sendo uma tarefa simples conquistar a confiança do usuário e estimular a sua participação na administração (Costa, 1998).

Outro obstáculo que merece ser mencionado é o da grande quantidade de demandas em saúde, que deve ter ocorrido principalmente devido ao caráter universal do SUS e da falta de implantação de serviços em número adequado. Curzel (2001) comenta a existência de uma relação inversamente proporcio- nal entre a demanda e a possibilidade de satisfação do usuário. Pinto e Lyra (2009) ponderam que, no Estado de São Paulo, as características dos serviços e o alto número de demandas dos setores da saúde, da segurança pública e da educação dificultam muito o trabalho das ouvidorias paulistas.

Incentivar a população à coparticipação e corresponsabilidade é muito mais viável se oferecemos ao usuário propostas factíveis e dentro da realidade, o que na prática pode ser um processo complexo para os prestadores de serviço público, porque normalmente os discursos teóricos são idealistas e imbuídos de perfeição - e talvez por esta razão eles sejam inicialmente bem recebidos. Porém, o desapontamento pode surgir se a realidade apresentada for muito diferente da teoria.

Um dado relevante foi o grande número de solicitações de informação nessa ouvidoria. Se o sistema de informações está insuficiente, há um provável problema na emissão dela pela instituição ou na recepção do usuário. Frente à constatação de que a ouvidoria está exercendo funções que seriam de um setor de informações, sugerimos a criação deste serviço, separadamente da ouvidoria. Estaríamos assim ajudando o cidadão a reconhecer a real função da ouvidoria, visto que esta vem realizando ações que não são de sua competência, e o seu verdadeiro papel pode estar sendo distorcido. Trabalhando dentro de suas legítimas funções, a ouvidoria enviaria aos órgãos competentes relatórios mais próximos da realidade, quanto às características das demandas.

Além disso, existe a hipótese de que a ouvidoria não esteja categorizando as manifestações de forma adequada, uma vez que 568 das 1.050 solicitações de informação e 168 das 226 reclamações diziam respeito a problemas com o acesso ou consultas, como já mencionado. Nesse caso as solicitações de informação seriam, na verdade, reclamações feitas de outra maneira ou com outra aparência. Assim, o maior problema sentido pela população na instituição pode ser a dificuldade de acesso ao tratamento, e não a falta de informação.

Outro dado importante é que alguns usuários creem que ao apresentarem suas queixas à ouvidoria contribuem para evitar que aquele problema reincida na instituição - essa ideia vem ao encontro dos princípios da precaução e da prevenção, evitando a 
ocorrência de novas reclamações, o que provavelmente desgastaria a imagem da instituição (Pereira e col., 2003). Esse dado parece revelar um aspecto positivo na questão da participação e da cidadania, tão comentada na literatura.

\section{Considerações finais}

As funcionárias entrevistadas demonstraram ter conhecimento dos motivos que levam o usuário a procurar a ouvidoria, mas a ideia de que, de um modo geral, esse usuário se satisfaz com um bom acolhimento pode não ser verdadeira. Acreditamos que,logo após o desabafo de seu problema na ouvidoria, talvez ocorra um alívio natural de emoções. Isso, associado à polidez dos ouvidores, poderia dar a impressão inicial de satisfação.

Por outro lado, a percepção dos usuários sobre os serviços da ouvidoria parece estar mais associada à solução de seus problemas e à crença de que trata-se de um setor superior ou, ao menos, tem poder de decisão. A solução do problema, quando ocorre, principalmente se é com brevidade, leva à satisfação desse usuário, enquanto que o oposto costuma levar à insatisfação e à desconfiança da efetividade do setor e dos que nele trabalham.

A demanda excessiva, causando principalmente dificuldade de acesso, torna muito complexa a resolução dos problemas dos usuários dessa instituição geriátrica e, portanto, o de sua ouvidoria. Sugerimos uma melhor organização do agendamento, dos serviços burocráticos e do fornecimento das informações ao cidadão, uma vez que essas ações dependem principalmente de iniciativas internas, da própria instituição. Ressaltamos a sugestão de uma das ouvidoras de capacitação e sensibilização permanentes dos funcionários da instituição quanto ao tratamento dispensado aos usuários idosos.

A ampliação da oferta de serviços à população geriátrica seria outra hipótese a ser considerada. A territorialização, ferramenta utilizada pela maioria das unidades de saúde do SUS, inclusive na instituição geriátrica pesquisada, normalmente uma estratégia apropriada para fins epidemiológicos e para o melhor estudo do processo saúde-doença, pode estar sendo excludente. Talvez a construção de instituições geriátricas em outros locais pudesse diminuir os problemas relacionados ao acesso.
Propomos finalmente que haja inclusão, como já sugerido, de dados qualitativos nos relatórios da ouvidoria e uma maior organização dos serviços, dado que o atual modo de classificação pode não estar correspondendo à realidade das demandas, fornecendo às instâncias superiores dados quantitativos inadequados para que ocorra uma política de melhora no atendimento.

\section{Referências}

BARDIN, L. Análise de conteúdo. Lisboa: Edições 70, 1979 .

BRASIL. Ministério da Saúde. Secretaria de Gestão Estratégica e Participativa. Orientações para implantação de ouvidorias do SUS. Brasília, DF, 2006.

BRASIL. Ministério da Saúde. Secretaria de Gestão Estratégica e Participativa. Política Nacional de Gestão Estratégica e Participativa no SUS: ParticipaSUS. Brasília, DF, 2009.

COSTA, F. L. A ouvidoria como instrumento para a efetividade da ação pública e a promoção da cidadania. Revista de Administração Pública, Rio de Janeiro, v. 32, n. 1, p. 163-170, 1998.

CURZEL, V. L'azione di marketing e i servizi per la salute. Punto Omega, Trento, v. 7, p. 61-81, dic. 2001.

GRUBBA, M. R. M. A humanização nas relações instituição-usuários nos hospitais da Secretaria de Estado da Saúde-SP, Brasil: análise do Programa Conte Comigo como um instrumento para o respeito à autonomia dos usuários. 2006. Dissertação (Mestrado em Ciências na área de Saúde Coletiva) - Coordenadoria de Controle de Doenças da SES/USP, São Paulo, 2006.

MARCONI, M. A.; LAKATOS, E. M. Técnicas de pesquisa. São Paulo: Atlas, 1988.

MINAYO, M. C. S.; DESLANDES, S. F.; GOMES, R. Pesquisa social: teoria, método e criatividade. Petrópolis: Vozes, 1993.

OMBUDSMAN SASKATCHEWAN. The history of the ombudsman. Regina, 2008. Disponível em: <http:// www.ombudsman.sk.ca/info/the-historyof-the-ombudsman>. Acesso em: 9 jun. 2010. 
PEREIRA, L. H. A voz do usuário no sistema hospitalar: ouvidorias. Sociologias, Porto Alegre, v. 4, n. 7, p. 82-121, 2002.

PEREIRA, M. M. C.; NÓIA, D. B. P.; OLIVEIRA, R. C. C. Ouvidoria: instrumento de eficiência empresarial e eficácia social do setor saneamento. In: CONGRESSO BRASILEIRO DE ENGENHARIA SANITÁRIA E AMBIENTAL, 22., 2003, Joinville. Anais... Joinville: Associação Brasileira de Engenharia Sanitária e Ambiental, 2003. Disponível em: <http://www.bvsde.paho.org/ bvsacd/abes22/cil.pdf>. Acesso em: 24 maio 2011.

PINTO, E.; LYRA, R. P. Modalidades de ouvidoria pública no Brasil. João Pessoa: Editora Universitária da UFPB, 2009.

RIBEIRO, M. A. F. O patrimonialismo na sociologia de Fernando Henrique Cardoso e o atraso brasileiro. Revista Eletrônica de Ciências Sociais, Uberlândia, v. 4, n. 9, p. 179-205, 2010. Disponível em: <http://www.editoraufjf.com.br/revista/index. php/csonline/article/view/535/485>. Acesso em: 23 maio 2011.
SÃO PAULO (Estado). Lei n ${ }^{0} 10.294$, de 20 de abril de 1999. Dispõe sobre proteção e defesas dos lares do serviço público do Estado de São Paulo e dá outras providências. Diário Oficial do Estado de São Paulo, São Paulo, 20 abr. 1999a. Seção I, p. 2.

SÃO PAULO (Estado). Decreto $n^{\circ} 44.074$, de $1^{\circ}$ de julho de 1999. Regulamenta a composição e estabelece competência das Ouvidorias de Serviços Públicos, instituídas pela Lei nº 10.294 , de 20 de abril de 1999, que dispõe sobre a proteção e defesa do usuário do serviço público do Estado de São Paulo. Diário Oficial do Estado de São Paulo, São Paulo, 2 jul. 1999b. Seção I, p. 1

SCANAGATTA, S. Cittadinanza e salute: la forza dell'opinione del cittadino nella sanità veneta. Milano: FrancoAngeli, 2009.

SILVEIRA, C.; AMARAL, D. P.; MARSIGLIA, R. M. G. Aspectos metodológicos sobre as intervenções junto aos segmentos sociais em situação de vulnerabilidade social: contribuição para a formação de redes sociais. In: SILVEIRA, C.; CARNEIRO JR, N.; MARSIGLIA, R. M. G. Projeto inclusão social urbana: nós do centro. São Paulo: Faculdade de Ciências Médicas da Santa Casa de São Paulo, 2009. p. 45-6o. 